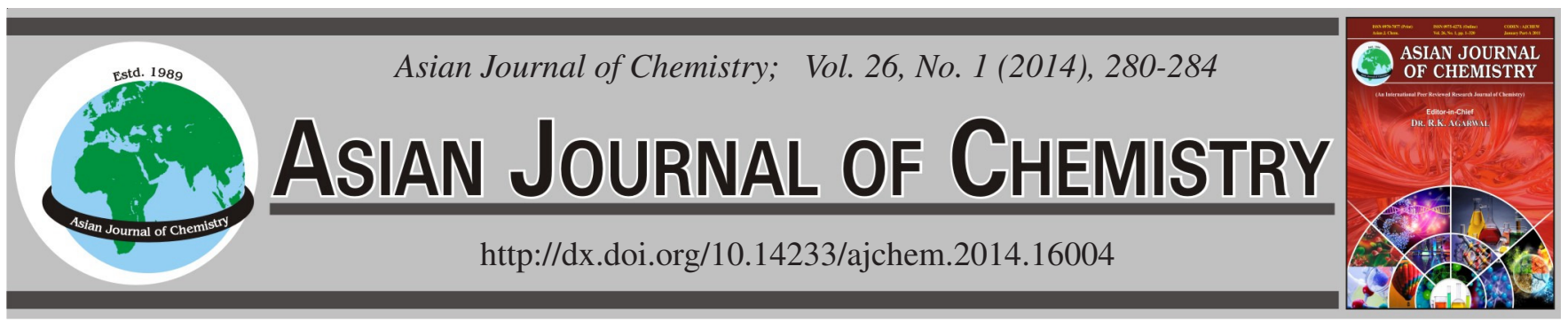

\title{
Identification of Bioconversion Products from Sosiho-Tang with Lactobacillus KFRI 129, 144, 442 and 693
}

\author{
K.J. LEE, H.J. YANG and J.Y. MA*
}

Korean Institute of Oriental Medicine, KM-Based Herbal Drug Development Group, 1672 Yuseongdae-ro, Yuseong-gu, Daejeon 305-811, Republic of Korea

*Corresponding author: Fax: +82 42 8689573, Tel: +82 42 8689466; E-mail: jyma@kiom.re.kr

\begin{abstract}
Sosiho-tang is a traditional herbal medicine consisting of seven medicinal herbs. The variation in the amount of useful components of Sosiho-tang and its bioconversion products (fermentation by Sosiho-tang) were determined by using high-performance liquid chromatography coupled with diode array detection (HPLC-DAD). Qualitative and quantitative analyses of the useful components of Sosihotang (liquiritin, liquiritigenin, baicalin, baicalein, glycyrrhizin and wogonin) were carried out using a $5 \mu \mathrm{m}, \mathrm{C}_{18}$ analytical column and were achieved by comparing their retention times $\left(t_{R}\right)$ and UV spectra with those of the standard compounds. In the results, the amount of baicalin in Sosiho-tang was five times more than the amounts of the other components. In addition, the amounts of two useful components, baicalin and liquiritigenin, increased by 2.96 and $1.92 \%$, respectively. Also, the amount of baicalein through fermentation showed the highest change compared with the amounts of the other components, decreasing from $81.38 \%$ to $41.01 \%$.
\end{abstract}

Keywords: Analysis, Bioconversion, HPLC-DAD, Sosiho-tang.

\section{INTRODUCTION}

The pharmacological effects of traditional medicines focus on the maintenance of good health, on disease treatment and on the enhancement of the body's resistance to disease ${ }^{1}$. Among the traditional medicines, Sosiho-tang (SO) has been widely used to treat chronic liver diseases like hepatitis ${ }^{2-6}$. This medicine consists of seven oriental medicinal herbs (OMHs): Bupleurum falcatum, Scutellaria baicalensis, Panax ginseng, Pinellia ternata, Glycyrrhiza uralensis, Zingiber officinale and Zizyphus jujuba. Bioconversion occurs through microorganisms, digestive enzymes and low gastric $\mathrm{pH}^{7-10}$. Moreover, the fermentation of herbal medicines caused by bioconversion maximizes the absorption of the useful components (e.g. isoflavones, saponins, phytosterols and phenols) of oriental medicinal herbs and enhances their biological activity. According to the related literature, research on the effect of fermentation with microorganisms on the quality and efficacy of oriental medicinal herbs is in progress ${ }^{11}$. Among the various well-known analysis techniques, such as thin-layer chromatography (TLC), high-performance liquid chromatography (HPLC), high-speed countercurrent chromatography (HSCCC) and capillary electrophoresis (CE), HPLC is the most widely used for the determination of the useful compounds in oriental medicinal herbs. In particular, the coupling of a diode array detector (DAD) and a mass spectrometer (MS) has been utilized as a useful and powerful analysis method of multiple herbal medicines ${ }^{12,13}$. In this study, qualitative and quantitative analysis screening of six useful components of Sosihotang were conducted using HPLC-DAD. Also, the variation of the components of Sosiho-tang after fermentation was determined. The useful components of the oriental medicinal herbs composed in this prescription, liquiritin, liquiritigenin, glycyrrhizin (Glycyrrhiza uralensis), baicalin, baicalein and wogonin (Scutellaria baicalensis), were selected for the analysis screening.

\section{EXPERIMENTAL}

The powder of Sosiho-tang was obtained from Korea Institute of Oriental Medicine. The standard compounds baicalin, baicalein, glycyrrhizin and wogonin were purchased from Korea Food and Drug Administration (KFDA). Liquiritin was obtained from Wako Pure Chemical Industries, Ltd. (Japan). Liquiritigenin was purchased from Chengdu Biopurify Phytochemicals, Ltd. (China). The purity (\%) of all the standard compounds was above $97 \%$. The HPLC-grade solvents, water and acetonitrile, were purchased from J.T. Baker (USA). The analytical-grade trifluoro acetic acid (TFA) was purchased from Sigma-Aldrich (USA). The chemical structures of the six useful components are shown in Fig. 1. 
<smiles>O=c1cc(-c2ccc(OC3OC(CO)[C@@H](O)C(O)C3O)cc2)oc2cc(O)ccc12</smiles>

Name: Liquiritin Formula: $\mathrm{C}_{21} \mathrm{H}_{22} \mathrm{O}_{9}$ m.w.: 418.39<smiles>O=c1cc(-c2ccc(O)cc2)oc2cc(O)ccc12</smiles>

Name: Liquiritigenin Formula: $\mathrm{C}_{15} \mathrm{H}_{12} \mathrm{O}_{4}$ m.w.: 256.26<smiles>COc1c(O)cc(O)c2c(=O)cc(-c3ccccc3)oc12</smiles>

Name: Wogonin

Formula: $\mathrm{C}_{16} \mathrm{H}_{12} \mathrm{O}_{5}$ m.w.: 284.26

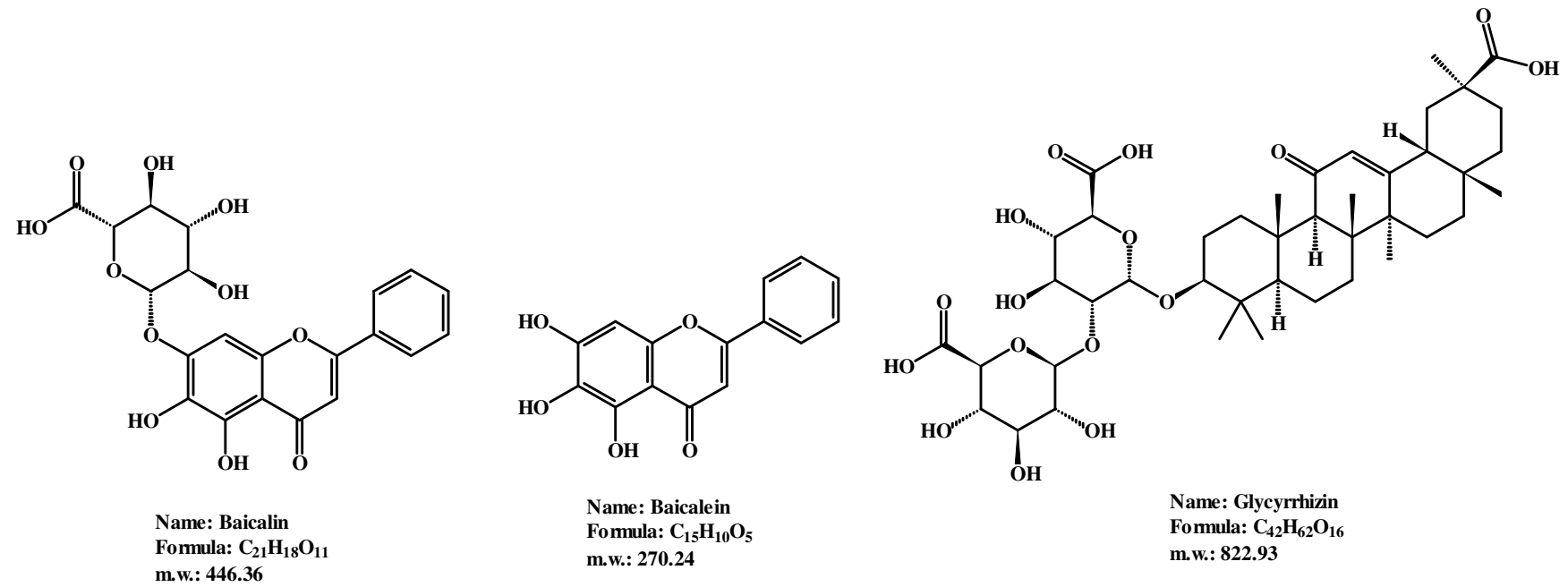

Fig. 1. Chemical structures of the six standard compounds in Sosiho-tang

Fermentation conditions of Sosiho-tang: Fermentation was conducted using the lactobacillus (KFRI strain Nos. 129, 144, 442 and 693) donated by Korea Food Research Institute (KFRI). After two successive transfers of the test organisms in MRS broth (lactobacillus broth acc. to De Man, Rogosa and Sharpe) for lactobacillus KFRI 129, 144, 442 and 693 for $24 \mathrm{~h}$ at $37{ }^{\circ} \mathrm{C}$, the activated cultures were again inoculated into each media under the same conditions. The cultures were diluted to obtain an initial population of $1-5 \times 10^{7} \mathrm{CFU} / \mathrm{mL}$ and were designated as the inoculums. The Sosiho-tang water extract was used as the culture media for fermentation after adjusting the $\mathrm{pH}$ to 7 using $1 \mathrm{M} \mathrm{NaOH}$ and was autoclaved for $15 \mathrm{~min}$ at $121^{\circ} \mathrm{C}$. After cooling, $750 \mathrm{~mL}$ Sosiho-tang was inoculated with $7.5 \mathrm{~mL}$ inoculum, as described above. This was incubated at $37{ }^{\circ} \mathrm{C}$ for a period of $48 \mathrm{~h}$. The Sosiho-tang was then passed through a $60 \mu \mathrm{m}$ nylon net filter (Millipore, MA, USA), precipitated overnight, lyophilized (supernatant) and stored in desiccators at room temperature prior to use. So, the extent of fermentation $\mathrm{pH}$ from Sosiho-tang and fermented Sosiho-tang were observed (Table-1).

TABLE-1 pH IN FERMENTED SOSIHO-TANG WITH LACTIC ACID BACTERRIA AT $37^{\circ} \mathrm{C}$ FOR $48 \mathrm{~h}$

\begin{tabular}{cc}
\hline Sample & $\mathrm{pH}$ \\
\hline Original Sosiho-tang (SO) & $7.00 \pm 0.00$ \\
Autoclave Sosiho-tang (ASO) & $6.08 \pm 0.00$ \\
FSO 129 & $4.34 \pm 0.00$ \\
FSO 144 & $4.16 \pm 0.00$ \\
FSO 442 & $4.23 \pm 0.00$ \\
FSO 693 & $4.27 \pm 0.01$ \\
\hline
\end{tabular}

Sample preparation: The standard solutions of the six useful components liquiritin, liquiritigenin, baicalin, baicalein, glycyrrhizin and wogonin were prepared at $200 \mu \mathrm{g} / \mathrm{mL}(200$ ppm) concentrations by dissolving them in methanol, respectively. The powdered Sosiho-tang was dissolved at a $50 \mathrm{mg} / \mathrm{mL}$ concentration in water, after which this suspension was filtered through a $0.2 \mu \mathrm{m}$ PVDF membrane filter before analysis. All the standard and sample solutions were stored at $4{ }^{\circ} \mathrm{C}$.

HPLC-DAD analysis conditions: HPLC analysis was conducted using the Elite Lachrom HPLC-DAD system equipped with an L-2130 pump, an L-2200 autosampler, an L-2350 column oven and an L-2455 photodiode array UV/VIS detector (Hitachi High Technologies Co., Tokyo, Japan). The output signal of the detector was recorded using the EZchrom Elite software (Version 3.3.1a) for Hitachi. Chromatographic separation of the useful components was carried out using an RS-Tech optimapak $\mathrm{C}_{18}$ column $(250 \times 4.6 \mathrm{~mm}$ I.D., $5 \mu \mathrm{m}$, Daejeon, South Korea) and the column temperature was kept at $40^{\circ} \mathrm{C}$. The mobile phase was composed of A: water/trifluoro acetic acid (99.9/0.1, vol. \%) and B: acetonitrile (100, vol. \%) with gradient elution. To improve the chromatographicseparation capacity, the mobile phase system performed the gradient elution as follows: $10 \%$ (0-5 min), 10-40\% (5-40 min) and $40 \%(40-60 \mathrm{~min})$ at a flow rate of $1 \mathrm{~mL} / \mathrm{min}$. The wavelength of the UV detector was set at 254 and $280 \mathrm{~nm}$ and the injection volume of each sample was $10 \mu \mathrm{L}$. The standard compounds liquiritin, liquiritigenin, baicalin, baicalein, glycyrrhizin and wogonin were confirmed via LC-MS analysis using Agilent 1100 + G1958 (Agilent Technologies, Inc. USA). 


\section{RESULTS AND DISCUSSION}

HPLC analysis conditions: HPLC analysis for the identification and separation of six useful components of Sosiho-tang was achieved. The analysis was carried out using a $\mathrm{C}_{18}$ column and the flow rate of the mobile phase was fixed at $1.0 \mathrm{~mL} /$ min. Gradient elution composition of water and acetonitrile were conducted to ideally separate each analysis peak. Acetonitrile was found to have a better analysis resolution than $\mathrm{MeOH}$. Also, trifluoro acetic acid $(0.1 \%, \mathrm{v} / \mathrm{v})$ was added to the water to lessen the peak tailing and to improve the ionization reaction. Thus, the addition of trifluoro acetic acid enhanced the separation capacity and sensitivity ${ }^{14}$. The UV wavelengths of the six components were set based on the maximum UV spectra absorption of each standard compound. Liquiritin, liquiritigenin, baicalin, baicalein and wogonin were detected at $280 \mathrm{~nm}$ respectively and glycyrrhizin was detected at $254 \mathrm{~nm}^{5,6}$. Fig. 2 shows that in the mixture of six components the components were successfully separated according to their polarity and were simultaneously analyzed. Also, the quality of each standard compound used in this analysis were confirmed by comparing the compounds molecular weights using LC-MS, as shown in Fig. 3.

Identification analysis of Sosiho-tang, autoclave treated Sosiho-tang (ASO) and fermented Sosiho-tang (FSO): The quantitative variations of the useful components in the bioconversion products from Sosiho-tang were determined via HPLC-DAD and their chromatogram are shown in Fig. 4. The identification of the useful components of the Sosiho-tang

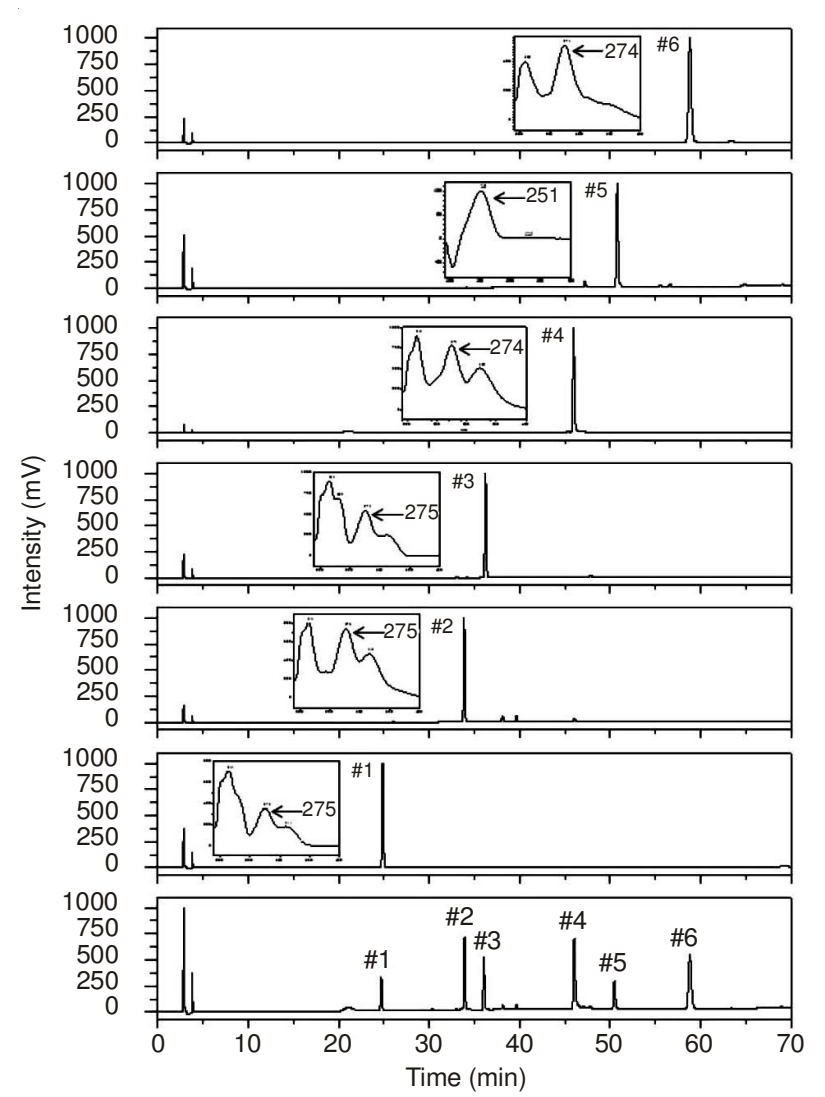

Fig. 2. Simultaneous analysis of liquiritin (1), baicalin (2), liquiritigenin (3), baicalein (4), glycyrrhizin (5) and wogonin (6) in a standard mixture via RP-HPLC-DAD

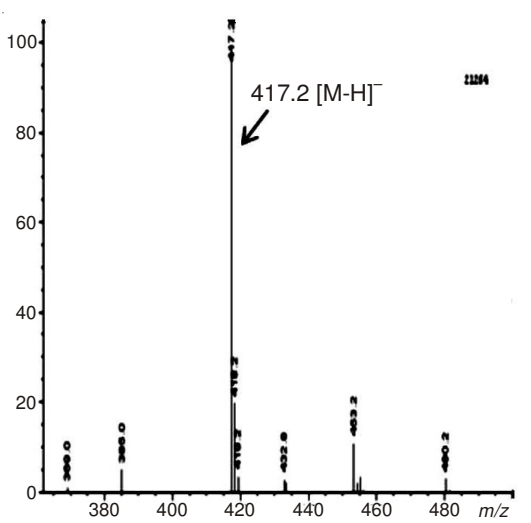

(1)

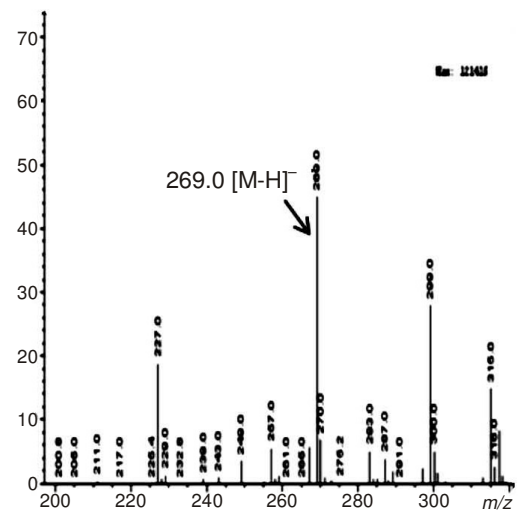

(4)

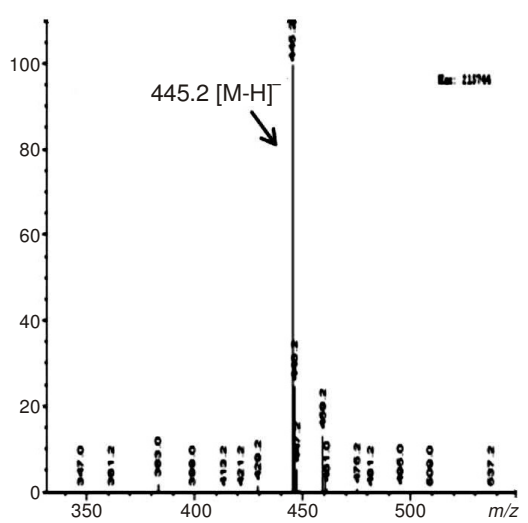

(2)

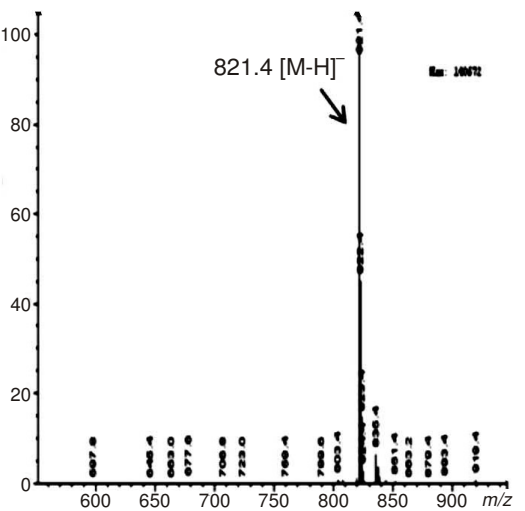

(5)

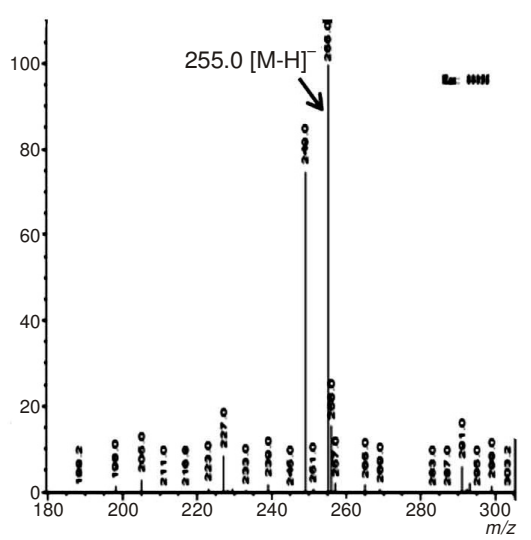

(3)

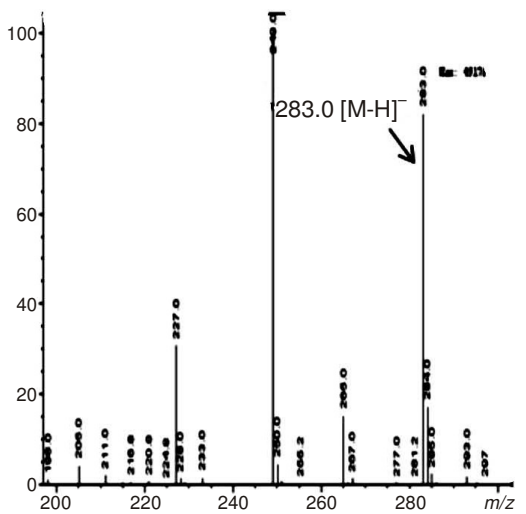

(6)

Fig. 3. LC-MS spectrum of the standard compounds liquiritin (1), baicalin (2), liquiritigenin (3), baicalein (4), glycyrrhizin (5) and wogonin (6) 


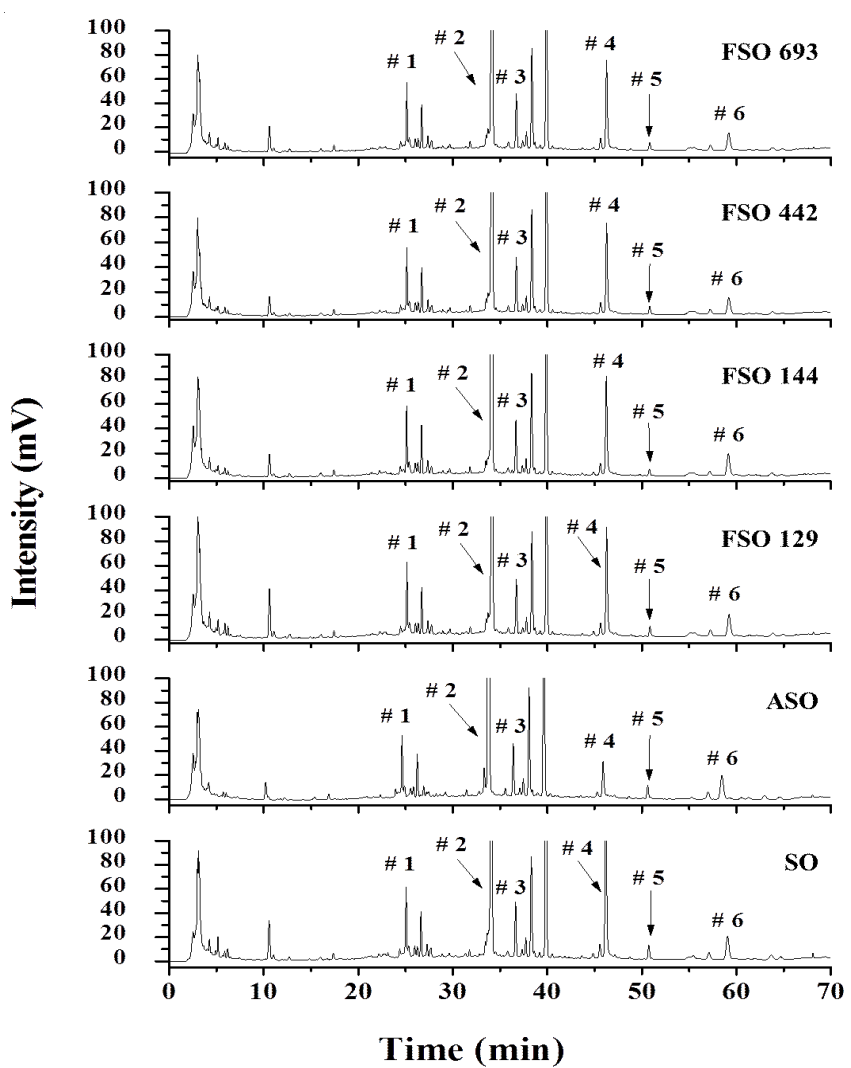

Fig. 4. Analysis screening of bioconversion products with four lactobacillus strains of liquiritin (1), baicalin (2), liquiritigenin (3), baicalein (4), glycyrrhizin (5) and wogonin (6) in the original Sosiho-tang, ASO and FSO samples via RP-HPLC-DAD

samples was based on the comparisons of their retention times $\left(t_{R}\right)$, UV spectra and chromatogram with those of the standard compounds. The profiles of the components liquiritin $\left(1, t_{\mathrm{R}}\right.$ : $25.01 \mathrm{~min})$, baicalin $\left(2, \mathrm{t}_{\mathrm{R}}: 34.01 \mathrm{~min}\right)$, liquiritigenin $\left(3, \mathrm{t}_{\mathrm{R}}\right.$ : $36.62 \mathrm{~min})$, baicalein $\left(4, \mathrm{t}_{\mathrm{R}}: 46.17 \mathrm{~min}\right)$, glycyrrhizin $\left(5, \mathrm{t}_{\mathrm{R}}\right.$ : $50.70 \mathrm{~min})$ and wogonin $\left(6, \mathrm{t}_{\mathrm{R}}: 59.03 \mathrm{~min}\right)$ were identified in the Sosiho-tang samples. The amounts of the useful components of the Sosiho-tang samples slightly changed during fermentation. The amounts of the six components were calculated based on their calibration curves. For the establishment of such curves, the serial injection volumes ( 2 to $40 \mu \mathrm{L}$ ) of the six standard solutions were analyzed in triplicate. The calibration curves were constructed by plotting the peak area $(\mathrm{Y}) v s$. the concentration of each analyzation $(\mathrm{x}, \mu \mathrm{g} / \mathrm{mL})$. The regression equations $(\mathrm{Y}=\mathrm{ax}+\mathrm{b})$ of each compound were calculated based on the calibration curves, respectively (shown not here). The good linearity of this method was confirmed by the correlation coefficient value $\left(r^{2}>0.9996\right)$. The identification of the six useful components of the original Sosiho-tang, autoclave treated Sosiho-tang and fermented Sosiho-tang samples are summarized in Table-2. Overall, all the useful components decreased during the autoclave treatment. Most of the components of Sosiho-tang generally increased compared with those of autoclave treated Sosiho-tang after fermentation and fermented Sosiho-tang 144 and 442 showed the highest increase. Glycyrrhizin and wogonin, however, showed an exceptional decrease in amount. Among the six analyzed screening components, baicalin was found to be the major component of Sosihotang. Its amount was five times higher than those of the other useful components. In contrast with the above results, glycyrrhizin and wogonin were detected in low micro amounts; the least amounts were 3.62 and $4.61 \mu \mathrm{g} / \mathrm{mL}$, respectively. Also, the amounts of baicalin and liquiritigenin increased by 2.96 and $1.92 \%$ after fermentation and those of the other components of Sosiho-tang had slight variations. The amount of baicalein after fermentation showed the highest change compared with those of the others. Its amount in Sosiho-tang also remarkably decreased during the autoclave treatment. It is known that this can be carried out at an autoclave system at a high temperature and pressure. This was expected to damage the cell walls that were in better contact with the extraction medium (Sosihotang). In addition, depending on the various engineering parameters, the useful components' yields increased and decreased, respectively. That of baicalein increased by $173.41-$ $216.38 \%$ compared to that of autoclave treated Sosiho-tang after fermentation. Thus, the reduction of baicalein is considered indicative of its instability at a high temperature $\left(120^{\circ} \mathrm{C}\right.$, autoclave condition) $)^{15,16}$.

\section{Conclusion}

The HPLC-DAD analysis successfully achieved the screening of the bioconversion products and the variations of

TABLE-2

IDENTIFICATION OF THE USEFUL COMPOUNDS IN THE ORIGINAL SOSIHO-TANG, AUTOCLAVE TREATED SOSIHO-TANG AND FERMENTATION SOSIHO-TANG

\begin{tabular}{|c|c|c|c|c|c|c|c|c|c|c|c|c|}
\hline \multirow[b]{2}{*}{ Component } & \multicolumn{2}{|c|}{$\begin{array}{c}\text { Original Sosiho- } \\
\text { tang }\end{array}$} & \multicolumn{2}{|c|}{$\begin{array}{c}\text { Autoclave treatment } \\
\text { Sosiho-tang }\end{array}$} & \multicolumn{2}{|c|}{$\begin{array}{c}\text { Fermentation } \\
\text { Sosiho-tang } 129 \\
\end{array}$} & \multicolumn{2}{|c|}{$\begin{array}{c}\text { Fermentation } \\
\text { Sosiho-tang } 144\end{array}$} & \multicolumn{2}{|c|}{$\begin{array}{c}\text { Fermentation } \\
\text { Sosiho-tang } 442 \\
\end{array}$} & \multicolumn{2}{|c|}{$\begin{array}{c}\text { Fermentation } \\
\text { Sosiho-tang } 693 \\
\end{array}$} \\
\hline & $\begin{array}{c}\text { Retention } \\
\text { time } \\
\left(\mathrm{t}_{\mathrm{R},}, \mathrm{min}\right)\end{array}$ & $\begin{array}{c}\text { Contents } \\
(\mu g)\end{array}$ & $\begin{array}{c}\text { Retention } \\
\text { time } \\
\left(\mathrm{t}_{\mathrm{R}, \mathrm{min}}\right) \\
\end{array}$ & $\begin{array}{l}\text { Contents } \\
(\mu g)\end{array}$ & $\begin{array}{l}\text { Retention } \\
\text { time } \\
\left(\mathrm{t}_{\mathrm{R},} \mathrm{min}\right)\end{array}$ & $\begin{array}{l}\text { Contents } \\
(\mu g)\end{array}$ & $\begin{array}{c}\text { Retention } \\
\text { time } \\
\left(\mathrm{t}_{\mathrm{R}}, \mathrm{min}\right) \\
\end{array}$ & $\begin{array}{l}\text { Contents } \\
\qquad(\mu \mathrm{g})\end{array}$ & $\begin{array}{c}\text { Retention } \\
\text { time } \\
\left(\mathrm{t}_{\mathrm{R},}, \mathrm{min}\right) \\
\end{array}$ & $\begin{array}{l}\text { Contents } \\
(\mu \mathrm{g})\end{array}$ & $\begin{array}{l}\text { Retention } \\
\text { time } \\
\left(\mathrm{t}_{\mathrm{R}, \mathrm{min}}\right) \\
\end{array}$ & $\begin{array}{c}\text { Contents } \\
(\mu g)\end{array}$ \\
\hline Liquiritin & 25.01 & $\begin{array}{l}13.534 \\
\pm 0.18\end{array}$ & 24.84 & $\begin{array}{l}10.456 \\
\pm 0.18\end{array}$ & 25.13 & $\begin{array}{l}11.578 \\
\pm 0.02\end{array}$ & 25.13 & $\begin{array}{l}12.983 \\
\pm 0.03\end{array}$ & 25.13 & $\begin{array}{l}13.066 \\
\pm 0.01\end{array}$ & 25.13 & $\begin{array}{l}12.751 \\
\pm 0.25\end{array}$ \\
\hline Baicalin & 34.01 & $\begin{array}{l}218.14 \\
\pm 0.10\end{array}$ & 33.9 & $\begin{array}{l}188.581 \\
\pm 1.82\end{array}$ & 34.13 & $\begin{array}{l}175.619 \\
\pm 0.36\end{array}$ & 34.13 & $\begin{array}{r}224.6 \\
\pm 3.22\end{array}$ & 34.13 & $\begin{array}{l}223.811 \\
\pm 0.12\end{array}$ & 34.13 & $\begin{array}{l}211.244 \\
\pm 3.61\end{array}$ \\
\hline Liquiritigenin & 36.62 & $\begin{array}{r}15.66 \\
\pm 0.06\end{array}$ & 36.49 & $\begin{array}{l}12.673 \\
\pm 0.28\end{array}$ & 36.73 & $\begin{array}{l}12.319 \\
\pm 0.01\end{array}$ & 36.73 & $\begin{array}{l}15.113 \\
\pm 0.18\end{array}$ & 36.73 & $\begin{array}{l}15.961 \\
\pm 0.01\end{array}$ & 36.73 & $\begin{array}{l}15.079 \\
\pm 0.25\end{array}$ \\
\hline Baicalein & 46.17 & $\begin{array}{l}41.109 \\
\pm 0.11\end{array}$ & 45.93 & $\begin{array}{l}7.657 \\
\pm 0.10\end{array}$ & 46.27 & $\begin{array}{l}20.934 \\
\pm 0.16\end{array}$ & 46.27 & $\begin{array}{l}24.224 \\
\pm 0.41\end{array}$ & 46.27 & $\begin{array}{l}22.455 \\
\pm 0.01\end{array}$ & 46.27 & $\begin{array}{l}21.592 \\
\pm 0.44\end{array}$ \\
\hline Glycyrrhizin & 50.7 & $\begin{array}{r}7.853 \\
\pm 0.01\end{array}$ & 50.6 & $\begin{array}{l}6.098 \\
\pm 0.06\end{array}$ & 50.86 & $\begin{array}{r}4.526 \\
\pm 0.01\end{array}$ & 50.86 & $\begin{array}{r}3.615 \\
\pm 0.07\end{array}$ & 50.86 & $\begin{array}{l}4.449 \\
\pm 0.01\end{array}$ & 50.86 & $\begin{array}{r}4.363 \\
\pm 0.07\end{array}$ \\
\hline Wogonin & 59.03 & $\begin{array}{r}6.089 \\
\pm 0.02 \\
\end{array}$ & 58.43 & $\begin{array}{r}5.407 \\
\pm 0.05 \\
\end{array}$ & 59.23 & $\begin{array}{r}4.62 \\
\pm 0.01 \\
\end{array}$ & 59.23 & $\begin{array}{r}5.859 \\
\pm 0.07 \\
\end{array}$ & 59.23 & $\begin{array}{r}4.654 \\
\pm 0.01 \\
\end{array}$ & 59.23 & $\begin{array}{r}4.606 \\
\pm 0.09 \\
\end{array}$ \\
\hline
\end{tabular}


each compounds in Sosiho-tang. The amount of baicalein through fermentation showed the highest change compared with the amounts of the other components. Also, the amounts of two useful components, baicalin and liquiritigenin, 2.96 and $1.92 \%$ increased, respectively. Thus, it is considered that the useful components yields through fermentation increased and decreased depending on the various engineering parameters (e.g., high temperature and pressure) as well as microorganisms. These results can be applied as the basic data for a study on the constituents of oriental medicinal herbs and traditional herbal medicines and on pharmacological evaluation from fermentation.

\section{ACKNOWLEDGEMENTS}

This study achieved in KIOM, KM-Based Herbal Drug Development Group, Also, this work was supported by the Study on drug efficacy enhancement using bioconversion for herbal medicines (K13050) project, the authors gratefully acknowledged.

\section{REFERENCES}

1. A.P. Lu, H.W. Jia, C. Xiao and Q.P. Lu, World J. Gastroenterol., 10, 1854 (2004).

2. H. Oka, S. Yamamoto, T. Kuroki, S. Harihara, T. Marumo, S. R. Kim, T. Monna, K. Kobayashi and T. Tango, Cancer, 76, 743 (1995).
3. C. Hirayama, M. Okumura, K. Tanikawa, M. Yano, M. Mizuta and N.A. Ogawa, Gastroenterol. Jpn., 24, 715 (1989).

4. S. Ueda, H. Nakamura, H. Masutani, T. Sasada, A. Takabayashi, Y. Yamaoka and J. Yodoi, Mol. Immunol., 38, 781 (2002).

5. N. Ohtake, M. Yamamoto, S. Takeda, M. Aburada, A. Ishige, K. Watanabe and M. Inoue, Eur. J. Pharmacol., 507, 301 (2005).

6. J.H. Kim, H.K. Ha, C.S. Seo, J.A. Lee and H.K. Shin, Kor. J. Herbology, 26, 41 (2011)

7. Y. Zhang, H. Wu, L. Li, J. Li, Z. Jiang, Y. Jiang and Y. Chen, J. Mol. Catal., B Enzym., 57, 130 (2009).

8. H.S. Kim, J.Y. Kim, M.S. Park, H. Zheng and G.E. Ji, J. Microbiol. Biotechnol., 19, 1650 (2009).

9. H. Kong, M. Wang, K. Venema, A. Maathuis, R. van der Heijden, J. van der Greef, G. Xu and T. Hankemeier, J. Chromatogr. A, 1216, 2195 (2009).

10. N.P. Niraula, S. Bhattarai, N.R. Lee, J.K. Sohng and T.J. Oh, J. Microbiol. Biotechnol., 22, 1059 (2012).

11. C. Liang, N.Y. Yun, S.W. Jung, D.S. Kim, Y.J. Lee and J.Y. Ma, Nat. Prod. Sci., 17, 363 (2011).

12. P. Drašar and J. Moravcova, J. Chromatogr. B Analyt. Technol. Biomed. Life Sci., 812, 3 (2004).

13. X.Y. Guo, J. Han, M. Ye, X.C. Ma, X. Shen, B.B. Xue and Q.M. Che, J. Pharm. Biomed. Anal., 63, 29 (2012).

14. Z. Yan, X. Yang, J. Wu, H. Su, C. Chen and Y. Chen, Anal. Chim. Acta, 691, 110 (2011).

15. D.O. Otieno, J.F. Ashton and N.P. Shah, Int. J. Food Microbiol., 115, 79 (2007).

16. S.M. Mahungu, S. Diaz-Mercado, J. Li, M. Schwenk, K. Singletary and J. Faller, J. Agric. Food Chem., 47, 279 (1999). 